\title{
Regularización de la tenencia del suelo urbano en brasil: Avances recientes y desafíos.
}

Paulo Avila ${ }^{1}$

\author{
Tipo de trabajo: Artículo
}

Material original autorizado para su primera publicación en el Journal de Ciencias Sociales de la Facultad de Ciencias Sociales de la Universidad de Palermo

Recibido 7-9-2012

Aceptado 24-10-2012

\section{Resumen}

Como trazo distintivo del proceso de urbanización en Brasil se observa en sus ciudades la proliferación de asentamientos informales de la población más pobre en donde la inseguridad de la tenencia de la vivienda está asociada a innumerables problemas sociales. A lo largo de los años Brasil tiene formulado dispositivos legales con el objetivo de promover el reconocimiento de los asentamientos informales como partes integrantes de las ciudades y de garantizar la tenencia del suelo urbano como forma de protección al derecho de la vivienda. El presente artículo traza un panorama de la evolución reciente del marco legal en el nivel federal para la regularización de la tenencia del suelo urbano y discute algunas cuestiones sobre lo que aún necesita ser hecho para mejorar los resultados de las políticas públicas de regularización como condición al desarrollo socioeconómico de las áreas urbanas.

Palabras-clave: viviendas informales, tenencia del suelo, asentamientos informales, legislación urbana, regularización del suelo.

\section{REGULARIZATION OF URBAN LAND TENURE IN BRASIL}

\section{Abstract}

As a remarkable trace of the urbanization process in Brazil it is notice within its cities the proliferation of informal settlements of the poorer population where insecure housing tenure is combined with countless social problems. All over the years Brazil has created legal tools driven to become possible the recognition of the informal settlements as integrated parts of the cities and to guarantee secure land tenure in order to protect housing rights. This paper traces an overview on the recent improvements made on the federal legal framework to regularize urban land tenure and discuss, in addition, remaining issues that have to be solved in order to enhance the results achieved by the public policies on land regularization as a condition to the social and economic development of the

\footnotetext{
${ }^{1}$ Magister en Planificación Urbanistica y Bachiller en Arquitectura y estudios urbanos, Universidad de Brasilia, Brasil. En la actualidad se desempeña laboralmente en el Ministerio de las Ciudades de Brasil, dedicado a la regularización de tierras de asentamientos urbanos informales. Es profesor asociado en el Departamento de Arquitectura del Instituto de Enseñanza Superior, Facultad Planalto (IESPLAN) Brasilia.

E-mail: avilapc@gmail.com o paulo.avila@cidades.gov.br
} 
urban areas.

Keywords: housing informality, land tenure, informal settlements, urban legislation, land regularization.

\section{Antecedentes}

La vivienda es uno de los artefactos físicos más importantes para la vida del ser humano, pues ejerce un papel estratégico en la organización de la vida social, desde el plan individual, en el establecimiento de condiciones adecuadas de satisfacción de necesidades básicas del individuo y de estructuración del núcleo familiar, hasta el plan colectivo, articulando en las relaciones entre la vivienda y la ciudad un complejo sistema de interacciones económicas y sociales, que consolida y reproduce en el territorio la propia dinámica de transformación de la sociedad.

Tanto en el plan individual cuanto en el colectivo la vivienda es un producto de gran significado económico. Mientras la casa propia es la principal forma de ahorro para la mayor parte de las familias, estimase que más del $80 \%$ de las existencias de capital fijo nacional es proveniente de las construcciones y su infraestructura asociada, siendo que la mayor parte es compuesta por las habitaciones. En las ciudades, cerca del $70 \%$ del área total está ocupada por las áreas habitacionales.

Varios son los factores que afectan la producción de viviendas urbanas y su acceso por parte de la población, con amplias repercusiones en la dinámica del desarrollo urbano. Entre esos factores pueden ser citados el tamaño de la población, la renta de las familias, sus gustos, sus perfiles y necesidades, la localización, la acción del gobierno en la provisión de infraestructura y servicios urbanos, la legislación de uso y ocupación del suelo, y las condiciones de financiación para producción y adquisición de viviendas.

Sin embargo, el acceso a la habitación por parte de los diferentes grupos sociales es asimétrico, siendo un aspecto intrínseco al crecimiento urbano la producción de una ciudad clandestina, marginada e ilegal, que es soportada por una demanda insolvente no atendida por las vías formales del mercado, implicando una ancha cadena de impactos sobre el bienestar individual y colectivo de las poblaciones que habitan los asentamientos informales.

La proliferación de asentamientos urbanos informales en diversas ciudades latinoamericanas viene en el rastro del fenomenal crecimiento urbano enfrentado por la región, con más intensidad en la segunda mitad del siglo 20. Según datos de la Cepal, en 1950 41,4\% de la población de América Latina y el Caribe era urbana, en 2010 ese total llega a 78,8\%. En Brasil, en 1950 apenas 36\% de los 52 millones de habitantes del país estaban viviendo en las ciudades, mientras en 1970 esta relación se invierte y el país presenta una tasa de urbanización del $56 \%$. En ese año, la población urbana de Brasil era equivalente a la población total de 1950. Según el Censo de 2010, Brasil hoy cuenta con cerca de 190 millones de habitantes, con $84 \%$ en las ciudades.

Así mismo considerando que el rápido proceso de urbanización brasileño fue promovido, básicamente, por contingentes poblacionales de bajos ingresos, las políticas públicas de planificación urbana y provisión habitacional fueron incapaces de inducir la producción de viviendas apropiadas en tipo, cantidad y localización adecuadas para esa población o de crear las condiciones para facilitar su acceso al mercado formal de viviendas.

Las restricciones de acceso a la vivienda legalizada por parte de los segmentos de menor renta 
no se dieron apenas por la baja capacidad financiera de esas poblaciones, pero también por las disfunciones de los mercados de suelo urbano de las ciudades brasileñas que resultaron en precios de viviendas elevados hasta mismo para las capas de renta media.

Para tener un orden de grandeza de cuán distorsionados son los precios de las viviendas en Brasil, Dowall (2006) indica que la relación entre los precios medios de las viviendas y la renta media domiciliar en 1998 en Brasil fue de 12,5. Esa relación, comparada entre 27 países de renta media en desarrollo, varió entre 1,7 (Polonia) a 20 (Lituania). La relación presentada por Brasil fue muy mayor de lo que todos los países en América Latina y Central, siendo menor apenas que Panamá, Serbia, Montenegro, Letonia, Costa del Marfil y Lituania. Por otro lado, 11 países de los 27 presentaron una relación abajo de 6, considerada una buena performance (Dowall, 2006).

Así, como trazo distintivo del paisaje de los principales centros urbanos brasileños se observa la ocupación por la población de baja renta de cuestas escarpadas, márgenes de ríos, áreas de manglares, áreas insalubres o contaminadas que ofrecen innumerables riesgos a sus ocupantes. Otro aspecto de la escisión socio-espacial de la ciudad son las periferias ocupadas por parcelaciones irregulares o clandestinas, desproveídas de infraestructura, equipos y servicios urbanos, cuyas áreas sin calidad espacial también son ocupadas por la población de baja renta.

En ese escenario, además de la inadecuación de la legislación brasileña para regular los mecanismos económicos de precios del suelo urbano, los instrumentos normalmente utilizados para control del uso y de la ocupación del suelo urbano producen más distorsiones. Estándares urbanísticos muy exigentes restringen la oferta de tipologías de viviendas adecuadas y accesibles a los más pobres, pasando la demanda de bajos ingresos a ser atendida al margen de la legislación. Al mismo tiempo, la acción negligente del poder público estimula la continuidad del ciclo de generación de la informalidad.

Varios autores apuntan que la gestión pública en Brasil ha sido arbitrariamente y selectivamente aplicada en las áreas urbanas. Maricato (1999) y Rolnik (1999) examinan la informalidad como un subproducto de la legislación y no como un desvío de la planificación, una vez que es aplicada de acuerdo con las circunstancias en una sociedad marcada por relaciones de favores y privilegios. La legislación de uso y ocupación del suelo estaría atraillada a la informalidad por el hecho de que en Brasil, históricamente, la ley busca estándares urbanísticos inalcanzables por la población de menor renta estando, muchas veces, ligada al servicio de intereses inmobiliarios (Rolnik, 1997 y Maricato, 1996).

Además de la legislación, la actuación del sector público en la urbanización brasileña se da de forma asimétrica. Mientras inversiones públicas y un riguroso control del uso del suelo son aplicados a las áreas donde predominan los grupos de mayor renta, preservando las calidades que hacen de esas áreas las mejores de las ciudades, las áreas periféricas empobrecidas son flagrantemente descuidadas por las inversiones públicas, donde el incumplimiento de la legislación urbanística no solo es tolerado como también estimulado.

Tanto en el caso de las favelas cuanto de las parcelaciones irregulares de tierra, la falta de seguridad de la posesión de las viviendas se liga a una ancha cadena de efectos que reproducen y agravan las condiciones de vulnerabilidad y pobreza urbana. El no reconocimiento legal de un asentamiento, y la falta de registro de sus inmuebles, se traduce en la falta de una dirección oficial y el no reconocimiento de sus moradores como ciudadanos. 
A partir de eso se desencadena una corriente de discriminación de los moradores de esas áreas en el acceso al mercado formal de trabajo, a servicios públicos y a las oportunidades de desarrollo ofrecidas en las ciudades, sobre todo, debido al estigma que los mismos cargan por vivir en áreas plenas de todo tipo de problemas sociales, criminalidad, degradación ambiental y otros.

La falta de la seguridad de la situación que expone las familias al riesgo de expulsión de sus casas, restringe la inversión en la mejoría de las condiciones habitacionales, mientras la amenaza de invasiones obliga a los responsables por los domicilios a permanecer en sus casas para protección del patrimonio. Tal efecto imposibilita que un adulto de la familia se inserte en el mercado de trabajo y exige, en muchos casos, que los niños salgan a las calles para lograr los recursos para la supervivencia de la familia, exponiéndolas a diversos riesgos.

También la falta de una dirección oficial dificulta la obtención de autorizaciones para el funcionamiento regular de pequeños negocios, impidiendo el desarrollo económico y la generación de empleo y renta en las áreas de asentamientos informales. La informalidad económica bloquea el acceso a líneas de financiación para ampliación de los negocios y cría obstáculos para que los empleados sean registrados, extendiendo la cadena de informalidad también a las relaciones laborales.

Es importante citar que la cuestión económica no es secundaria en los asentamientos informales. En la medida en la que esos asentamientos se consolidan, sean favelas o parcelaciones irregulares, crecen las inversiones privadas siendo importante para la mejoría de los barrios, para la seguridad y valorización de los inmuebles (Guedes y Oliveira, 2006). Eso hace que las actividades económicas que generan colocaciones en esas localidades, reduciendo también la dependencia con relación a otras áreas de la ciudad, sea un factor importante para a sostenibilidad de esos asentamientos.

La vivienda en los asentamientos de población más pobre se constituye en la principal forma de ahorro y movilidad social (Guedes y Oliveira, 2006). En esos asentamientos, la casa es progresivamente construida y mejorada con las pequeñas inversiones de las familias a lo largo de los años. Por lo tanto, es importante que la casa sea, efectivamente, convertida en activo financiero, capacitando económicamente esa población en la busca de fuentes de recursos en la forma de crédito para la realización de mejorías en las condiciones de las habitaciones o para aplicación en otras inversiones.

Como destaca De Soto (2001) cuando los derechos de propiedad no son adecuadamente registrados, empresas que no poseen constitución legal y familias que no poseen una dirección verificable no consiguen transformar sus activos en capital. Esa laguna, no permite que los inmuebles sean negociados fuera de los angostos círculos locales, impidiendo el uso del patrimonio construido como garantía de empréstitos y participación en inversiones. Como resultado, los asentamientos informales, empresas y familias son poco capitalizadas y no consiguen romper el círculo de inseguridad que caracteriza las relaciones locales dominadas por la informalidad, baja capacidad financiera y relaciones económicas y de trabajo precarias.

La solución para la inseguridad de la posesión de las viviendas urbanas de baja renta debe ser encarada como uno de los pilares de la política habitacional de los países de América Latina. Ella es condición fundamental para el rescate de la ciudadanía de las poblaciones urbanas más pobres, el combate a la pobreza urbana y la plena integración de esas poblaciones a la ciudad y a la sociedad.

En ese sentido, Brasil ha avanzado en la remoción de obstáculos legales que impedían 
acciones de regularización de la tierra urbana más efectivas, al mismo tiempo en el que implantó políticas federales de apoyo a acciones de regularización descentralizadas, envolviendo estados, municipios y organizaciones no gubernamentales. Tales avances fueron, en gran medida, fruto de la movilización y de la presión de los diversos segmentos de la sociedad que cobraban una acción más activa del gobierno federal para enfrentar el problema de la informalidad urbana.

Sin embargo, pese a la experiencia acumulada a lo largo de los últimos años por sectores del gobierno federal y de los avances alcanzados, aún mucho debe ser hecho, puesto que la magnitud y la diversidad de los problemas relacionados a la tenencia del suelo urbano, exige acciones en la esfera jurídica, urbanística, ambiental, social y económica.

\section{2 -El cuadro de irregularidad de la tierra urbana en Brasil}

La regularización de una propiedad está vinculada, en principio, a cómo garantizar a quien ocupe de hecho un pedazo de suelo su dominio, evitando remociones forzadas, desahucios e invasiones de terceros. Se trata, antes de todo, de asegurar la posesión como forma de garantizar un derecho real a quien, de hecho, ya ejerce un dominio útil de determinada parcela de tierra. Hoy el país cuenta con diversos instrumentos para efectivizar la protección de la posesión de un inmueble. Sin embargo, los problemas asociados con la inseguridad de la tenencia del suelo no se encierran en la resolución apenas de la cuestión patrimonial, una vez que para la satisfacción de las diversas necesidades del ser humano, otros aspectos deben ser considerados.

La regularización de la tenencia del suelo urbano debe abordar el problema de una forma sistémica exigiendo acciones amplias que pasan por diversas dimensiones, como la jurídica, la administrativa, la urbanística, la ambiental, la social y la económica. En ese sentido, la cuantificación y la calificación de los problemas presentes en los asentamientos informales no es fácil, vista la laguna de levantamientos específicos que retracten la situación en todos sus posibles aspectos.

En un primer momento, algunos números de la pesquisa del Perfil de los Municipios de Brasil, realizada en 2008 por el IBGE (Instituto Brasileño de Geografía y Estadística), permiten mirar un poco el escenario de informalidad urbana en el país. De los 5.564 municipios brasileños en 2008, $33 \%$ afirmaron poseer favelas y $53 \%$ de tener parcelaciones de tierras irregulares o clandestinas. Considerando el total de los municipios con alguna ocurrencia de favelas o parcelaciones irregulares o ambos tenemos cerca del $59,8 \%$ de los municipios en esa situación.

La ocurrencia de favelas y asentamientos irregulares se vuelve más crítica cuanto mayor el tamaño de las ciudades. En los 1.014 municipios con población urbana de 20 mil habitantes o más, $67 \%$ relataron la existencia de favelas, mientras $78 \%$ relataron poseer asentamientos irregulares. De esos, $85 \%$ anunciaron poseer o favelas, o parcelaciones irregulares o ambos.

Ya en los municipios que presentaban más de 100 mil habitantes, $87 \%$ de ellos afirmaron poseer favelas y $92,5 \%$ poseían parcelaciones irregulares, según muestra la figura 2 . Esos municipios, que totalizaban 227 en 2007, representaban apenas 4,7\% de los municipios brasileños, pero concentraban cerca del $60,5 \%$ de la población urbana del país o 92,7 millones de personas. De esos municipios, 214 confirmaron la ocurrencia de favelas o parcelaciones irregulares o ambas formas de ocupación informal. 


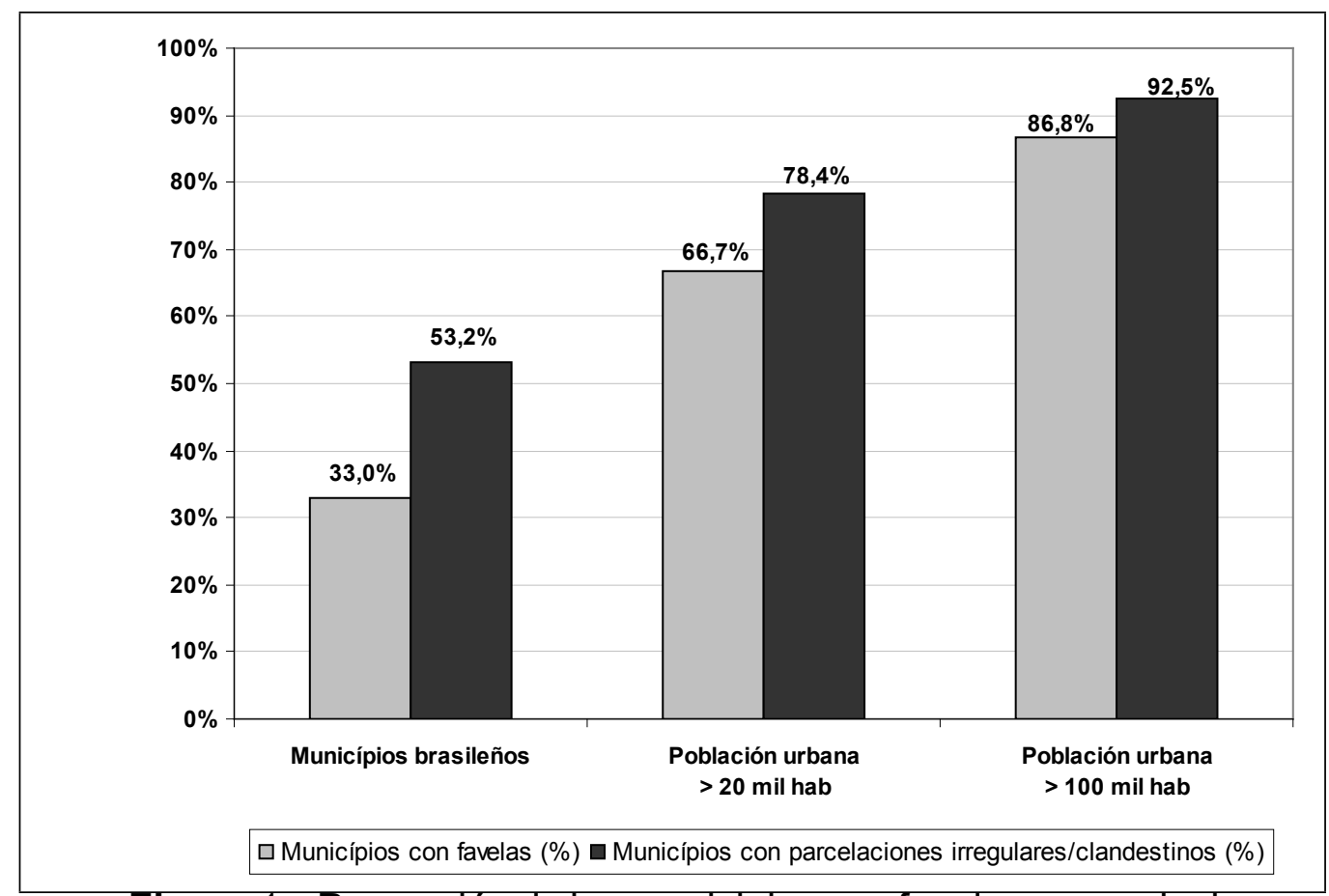

Figura 1-Proporción de los municipios con favelas y parcelaciones irregulares.

Fuente: IBGE. Perfil de los Municipios Brasileños 2008.

Por otro lado, el Censo Demográfico que plantea un perfil de los domicilios brasileños, no presenta datos exactos que permita cuantificar y calificar el total de domicilios con situación precaria de la tenencia del suelo en todas sus dimensiones. En lo que se refiere al registro inmobiliario, la excepción de algunos catastros municipales, cuando existen, el levantamiento nacional no mide objetivamente si una vivienda está regular o no. El Censo Demográfico de 2000, por ejemplo, a lo más cuestiona en cuanto a la condición de ocupación del domicilio, si la vivienda o el terreno es propio o no. En el Censo de 2010, la pregunta sobre la posesión del terreno fue descontinuada.

En esos casos, las respuestas pueden reflejar la percepción subjetiva que los entrevistados tienen con relación a la tenencia del inmueble, no quedando la cuestión objetivamente contestada. Así mismo, no habiendo certificación, los entrevistados pueden considerar que tanto la casa cuanto el respectivo terreno son propios, una vez que fueron adquiridos de buena fe por compra de lotes de los parceladores de tierras o son ocupados por décadas sin negación. Esos levantamientos también no traen una clasificación de la localización de los domicilios, si situados en favelas, parcelaciones irregulares o clandestinas.

Los datos del censo de 2000 referentes a las condiciones de ocupación del domicilio o del terreno apuntaban cerca de 2,6 millones de domicilios en áreas urbanas cuya condición de ocupación fuese incierta, esto es, viviendas propias en terrenos no propios, o viviendas sin condiciones de ocupación formalmente establecidas. Esos datos, muy probablemente, subestiman el total de viviendas irregulares en el país.

Otra información que no refleja la real situación de la informalidad en Brasil es la que se refiere a los llamados aglomerados subnormales, definición que el IBGE utiliza para identificar un tipo de sector especial del censo con el propósito de planificación de las pesquisas y cálculo de los costos de la recogida de datos en situaciones espaciales específicas. Los sectores especiales 
en aglomerados subnormales son definidos anteriormente a las pesquisas, teniendo como base los sectores especiales de las pesquisas anteriores, ajustadas con informaciones actualizadas por los municipios, cuando existen. Estudiosos del tema afirman que los datos de los aglomerados subnormales son subenumerados, desde que no consideran las áreas de parcelaciones clandestinas e irregulares.

El estudio realizado en 2007 por el Centro de Estudios de la Metrópolis sobre datos del censo de 2000 en 561 municipios de regiones metropolitanas, municipios con más de 150 mil habitantes y otros escogidos por el Ministerio de las Ciudades, buscó comparar características demográficas, socioeconómicas y de las casas de los domicilios particulares permanentes en los sectores no especiales del censo que fuesen semejantes a las encontradas en los sectores censales de los aglomerados subnormales. El estudio encontró, además de los 1,62 millones de domicilios de los aglomerados subnormales, otros 1,55 millones de domicilios con características semejantes de los sectores normales, totalizando cerca de 3,17 millones de domicilios llamados precarios, que prácticamente dobla el número de los primeros.

De acuerdo con los resultados preliminares del censo demográfico de 2010, había cerca de 3,2 millones de domicilios en aglomerados subnormales, siendo que más del $95 \%$ de ese total estaba localizado en áreas urbanas. Aunque ese número duplique el total encontrado en 2000, el IBGE alerta que en 2010 fue utilizada metodología diferente de la utilizada en 2000, por lo tanto, esos números no pueden ser comparados directamente. De acuerdo con los datos de 2010, cerca de 11 millones de personas, o 6\% de la población de Brasil, viven en favelas.

La Fundación João Pinheiro, otro órgano de pesquisa brasileño, con base en los números de la PNAD (Pesquisa Nacional de Muestra de Domicilios) de 2007, estima que el déficit de viviendas en Brasil sea del orden de 6,3 millones de unidades, siendo que en las áreas urbanas este número es de cerca de 5,2 millones (Fundación João Pinheiro, 2009). Por otro lado, el mismo estudio apunta que en 2007 existían cerca de 10,5 millones de domicilios urbanos que no disponían de uno o más servicios de infraestructura (agua, alcantarillado, colecta de basura o red eléctrica y alumbrado) y cerca de 1,88 millones con inadecuación en la tenencia del suelo, características normalmente vinculadas a los asentamientos informales.

En el cálculo de los domicilios urbanos inadecuados no son incluidos aquellos clasificados en situación de déficit de viviendas por causa de su estructura física - improvisadas y rústicas (Fundación João Pinheiro, 2009). Muchos domicilios en situación de déficit por su estructura física, por lo tanto, también pueden ser inadecuados con relación al acceso a los servicios básicos de infraestructura o a su tenencia, o a ambos.

El hecho es que la situación de viviendas sin registro en el país es, probablemente, muy superior a los datos de déficit de viviendas. Esta constatación tiene implicaciones importantes para la política habitacional. Según las características de la producción de viviendas de la población de baja renta, efectuada por la mejoría gradual de las construcciones a lo largo del tiempo por los propios moradores, una parcela importante del déficit de viviendas podría ser enfrentada no por la construcción en escala de nuevas casas, por medio de la financiación de grandes empresas de construcción con recursos públicos, sino desde acciones que se iniciarían con la regularización de la tenencia del suelo.

La seguridad de la tenencia y la preservación del derecho a la vivienda sería el elemento 
estratégico a dar la seguridad necesaria para que los moradores invirtiesen en la mejoría de sus residencias. Esas inversiones serían hechas con recursos propios o desde líneas de crédito para adquisición de materiales de construcción subvencionados y también por los incentivos fiscales que retiren impuestos de los precios de materiales de construcción. Así, el déficit habitacional podría reducirse, especialmente en la parcela de las viviendas identificadas como precarias o que necesita reposición debido a la depreciación.

3 - Evolución del marco legal en Brasil para la regularización de la tenencia del suelo urbano

Desde las décadas de 5060 del siglo pasado, cuando la industrialización y el rápido proceso de urbanización habían alterado radicalmente el paisaje urbano de las principales ciudades de Brasil dando origen a grandes áreas metropolitanas, el problema de los asentamientos informales y favelas ya atraían mayor atención de los gobiernos y pesquisidores.

En ese período, varias propuestas fueron presentadas por gobiernos para la solución del problema de las favelas obedeciendo, básicamente, a dos líneas de acción: la urbanización de las favelas, como medio de mejorar las condiciones de vida de sus moradores, integrándola gradualmente a la ciudad; u otra línea, que proponía la remoción de sus moradores para otro local con la construcción de nuevas unidades habitacionales. Los defensores de esa línea creían que no sería posible a los moradores de las favelas ser integrados a la sociedad en un ambiente degradado; y mientras una persona morase y viviese de aquel modo siempre serían vistos como "favelados" (Perez, 2007).

En medio del proceso de redemocratización del país, ganan fuerza los movimientos de defensa de la población de las favelas y el enfoque que defendía la consolidación y la urbanización de los asentamientos precarios.

\section{Primeras experiencias efectivas de regularización de la tenencia del suelo}

Los movimientos de defensa de la población de las favelas influenciaron experiencias pioneras de regularización de asentamientos informales y favelas desde el inicio de la década de 1980, como lo PREZEIS (Plan de Regularización de las Zonas Especiales de Interés Social) en Recife (1983) o el Programa de Regularización de Favelas (PROFAVELA) en Belo Horizonte (1984). Otras ciudades también implementan programas semejantes, como Diadema y Rio de Janeiro por medio de las respectivas procuradurías estaduales. La tenencia del suelo y el derecho de permanencia en los locales eran los principales puntos defendidos por los movimientos de defensa de las favelas (Brasil, 2005).

Esas intervenciones contemplaban básicamente la incorporación urbanística del asentamiento a la ciudad por medio de su delimitación en áreas especiales en la división de las zonas urbanas, las Ilamadas Zonas o Áreas Especiales de Interés Social (ZEIS, AEIS, etc). En tales áreas, eran reconocidas sus características particulares, a despecho de las restricciones y de la rigidez de los parámetros de uso y ocupación del suelo, lo que posibilitaba su regularización según criterios propios. Tales instrumentos se volvieron viables desde la Ley de Parcelación del Suelo para fines Urbanos, de 19 de diciembre de 1979. 
La ley de parcelación del suelo no trataba directamente de la regularización, pero traía la posibilidad de flexibilizarse los parámetros mínimos de parcelación establecidos en la ley cuando la parcelación se destinase a la urbanización específica o edificación de conjuntos de viviendas populares. También establecía que el gobierno local podría asumir la regularización de parcelaciones no autorizadas o ejecutadas en desconformidad con el proyecto aprobado, y los lotes registrados en nombre de los adquirentes.

La ley de parcelación del suelo de 1979 era parte de una tentativa de implantación de un rito regulatorio para el desarrollo urbano del país propuesto por el gobierno federal, por medio de la creación de dos leyes nacionales que definirían el Sistema Nacional de Desarrollo Urbano: La Ley Nacional de Parcelación del Suelo y la Ley Nacional de Desarrollo Urbano. Mientras la primera fue aprobada en 1979 , dando origine a la Ley $n^{\circ} 6.766$, la segunda, presentada por el Ejecutivo como Proyecto de Ley 775 en el Congreso en 1983 fue cercada de polémica y de fuerte resistencia de diversos sectores. Conocida como Ley de Uso del Suelo el Proyecto de Ley nunca entró en la pauta de votación del Congreso Nacional. Sin embargo, muchos de sus dispositivos vendrían a componer el Estatuto de la Ciudad casi 20 años después.

Posteriormente, la Ley n 9.785, de 1999, que alteró la ley de parcelación del suelo admitió la posibilidad de una zona específica (Zonas Habitacionales de Interés Social - ZHIS) que flexibilizaba aún más las exigencias para parcelación, especialmente en lo que atañe a la provisión de la infraestructura básica para nuevas habitaciones de interés social y la regularización de asentamientos precarios. La nueva ley también reconoció el interés público de las acciones de regularización de la tenencia, promovidas por los gobiernos locales.

La regularización, entonces, se daba por el reconocimiento y aprobación de la parcelación del suelo de acuerdo con criterios particulares a cada asentamiento, de la definición individual de cada lote o vivienda, siendo entonces asegurada la posesión de las viviendas a cada familia, en la mayor parte de las veces, por medio de la Concesión del Derecho Real de Uso (CDRU), con base en el Decreto-Ley 271, de 1967 (Brasil, 2005).

La regularización del asentamiento, en general, también era acompañada de intervenciones del poder público en la provisión de infraestructura y construcción de equipos públicos (escuelas, centro de actividades, asistencia social, puesto policial, canchas y otros), para servicio de las demandas sociales de las poblaciones de esas áreas.

No obstante la preocupación con la regularización de la tenencia del suelo, algunos programas privilegiaron el enfoque de urbanización, para transformación de las favelas en barrios populares, dejando la cuestión de la propiedad para otra etapa. Uno de esos programas es el Favela-Barrio, implantado en Río de Janeiro en 1994, soportado por el BID que ya tenía la experiencia de los Programas de Mejoramientos de Barrios, iniciados en Chile en los años 80.

\section{El Capítulo de la Política Urbana en la Constitución Federal de 1988}

Consecuente de algunas experiencias con éxito después de la ley 6.766, de 1979, y, especialmente, del esfuerzo de los movimientos de defensa de la reforma urbana fue la inclusión del Capítulo de la Política Urbana en la Constitución Federal de 1988, artículos 182 y 183. Esos artículos establecen en líneas generales instrumentos para ordenar el desarrollo de las ciudades según los 
principios de la función social de la propiedad y de la ciudad, definiendo el Plano Director como el instrumento básico del desarrollo y de la expansión urbana y la usucapión especial urbana.

La usucapión especial urbana garantiza la tenencia de área de hasta 250 metros cuadrados utilizada para vivienda de aquél que la ocupa o de su familia, de forma mansa y pacífica, sin oposición o interrupción por el plazo mínimo de 5 años. La institución de la usucapión urbana por vía constitucional es fundamental para la efectiva protección del derecho a la vivienda.

Aunque la adquisición del dominio por la usucapión dependa del reconocimiento de un derecho y su confirmación en juicio, ese instrumento abre la posibilidad de adquirirse una propiedad por la posesión del inmueble, forma original de adquisición de la propiedad antes de la Ley de Tierras (1850). Esta ley estableció la compra como forma de adquisición de una propiedad, surgiendo de allí la necesidad del registro inmobiliario, de modo a dar seguridad jurídica a las transacciones de tierras.

La institución de la usucapión especial urbana es derivada de la introducción de la función social de la propiedad, establecida en el artículo $5^{\circ}$ de la Constitución. La función social de la propiedad supera la visión civilista del derecho de propiedad que lo consideraba como un derecho absoluto e ilimitado, perpetuo y exclusivo, por el cual una cosa queda sometida a la voluntad de una persona que decide cuándo usar, fruir o disponer de un bien. Si el derecho de propiedad es exclusivo e ilimitado, el propietario también tendría el derecho exclusivo e ilimitado de no usar, no gozar y no disponer de su propiedad.

La propiedad del suelo urbano concreta una centralización individual de los derechos sobre el uso de la tierra, por oposición a una gran diversidad o multiplicidad de relaciones jurídicas de la tierra con aspectos sociales y económicos de una sociedad. Mientras la propiedad es, de hecho, un derecho individualizado garantizado por la Constitución, el ejercicio de ese derecho depende del contexto histórico y del sistema jurídico y normativo vigente, como bien define las palabras del jurista Celso Bandeira de Mello (1982, p. 27):

El derecho de propiedad es el resultado del régimen constitucional y legal de la propiedad. En esto nada hay de particular, puesto que la noción de 'derecho' postula la idea de limitaciones, de contenciones. El derecho de propiedad, entonces, es la expresión jurídica de la propiedad, lo que equivale a decir que es la propiedad tal como configurada en un dado sistema normativo.

Decurso de este entendimiento es la forma de tratamiento de la propiedad urbana y la separación entre derecho de propiedad y el derecho de construir. La edificabilidad no es algo "natural" al terreno, sino una creación de la actividad urbana que es limitada o condicionada por el sistema de normas que regulan el desarrollo de las ciudades, establecido en planes directores y otros dispositivos normativos. Esto lleva a la vinculación del derecho de propiedad a la función por él ejercido y a su función social.

La función social de la propiedad está vinculada, entonces, a obligaciones positivas del ejercicio del derecho de propiedad delante de los demás, prevaleciendo el interés público sobre los intereses individuales, abandonando la idea de que el derecho de construir deriva directamente del derecho de propiedad. De esa forma, el papel que la propiedad urbana irá a cumplir dentro de la ciudad y, por 
lo tanto, las limitaciones y deberes que son impuestos al propietario, estará predeterminado en los dispositivos urbanísticos de acuerdo con el interés colectivo.

Desde la Constitución Federal de 1988 la propiedad pasa a ser vista como un complejo de normas de Derecho Público y de Derecho Privado, notadamente de Derecho Constitucional, donde el principio de la función social incidirá diferentemente en cada categoría de la propiedad pública, privada, agrícola, industrial, rural y urbana.

En 2000, por medio de la Enmienda Constitucional $n^{\circ} 26$, el derecho a la vivienda pasa a pertenecer al rol de los derechos sociales constitucionales, establecidos en el artículo $6^{\circ}$. Diferentemente de los derechos individuales, que para su concretización exige apenas que el Estado se abstenga de algo; los derechos sociales, al contrario, para que se tornen efectivos exigen una intervención directa del Estado. Así, la constitucionalización de derechos sociales es un fuerte elemento de presión para que los gobiernos, por medio de las políticas públicas, garanticen la efectividad de esos derechos.

Eso se aplica, por ejemplo, en la cuestión de la regularización de la tenencia puesto que pasa a ser un deber del Estado en el ámbito de la garantía y efectuación del derecho constitucional de morada a los ocupantes de determinadas áreas. La intervención en la regularización de la tenencia se coloca también como fundamental en el cumplimiento de la función social de la propiedad.

\section{El Estatuto de la Ciudad y el nuevo Código Civil}

A lo largo de los años 1990 la cuestión de la regularización de la tenencia del suelo urbano y de la urbanización de asentamientos precarios gana cuerpo y las experiencias se vuelven más robustas. Los programas de Recife, Belo Horizonte y Diadema se consolidan, surgen nuevas experiencias en Santos y Natal, el Favela-Barrio, programa de gran alcance en la urbanización de las favelas del Rio de Janeiro, y en otras ciudades.

Paralelamente, el rito legal que proporciona sustentación a las acciones de regularización urbana es perfeccionado con el Estatuto de la Ciudad, Ley $\mathrm{n}^{\circ}$ 10.257, de 2001, que reglamenta los artículos 182 y 183 de la Constitución Federal, compilando, en nivel nacional, diversos instrumentos de planificación y desarrollo urbano.

Así es que el Estatuto de la Ciudad establece en las directrices generales para el desarrollo de las funciones sociales de la ciudad y de la propiedad la regularización de la tenencia y la urbanización de áreas ocupadas por población de bajos ingresos mediante el establecimiento de normas especiales de urbanización, uso y ocupación del suelo y edificación. Tal flexibilización es posible por medio de la institución por el Estatuto de las Zonas Especiales de Interés Social (ZEIS) como instrumento jurídico y político.

En 2001, visando ajustar el texto que originalmente había sido propuesto por el Estatuto de la Ciudad, pero que fue vetado por ocasión de la sanción presidencial, la Medida Provisoria $n^{\circ} 2.220$, de 2001 instituyó la Concesión de Uso Especial para fines de Morada, la CUEM. Diferentemente de la Usucapión Especial Urbana individual y colectiva instituidas por la Constitución Federal y por el Estatuto de la Ciudad, respectivamente, que se aplican a las áreas privadas, el nuevo instrumento se aplica, básicamente con las mismas reglas, a las áreas públicas, siendo concedido por vía administrativa en el órgano competente de la Administración Pública.

Otro avance importante ocurrido después del Estatuto de la Ciudad es el nuevo Código Civil, 
Ley $n^{\circ} 10.406$, de 2002, que coloca el derecho de propiedad como exclusivo y pleno, pero no más ilimitado. El ejercicio de este derecho queda dependiente de sus finalidades económicas y sociales, y también con el establecido en ley especial en lo que toca a la preservación ambiental y del patrimonio histórico y artístico.

El nuevo Código Civil también establece que el propietario puede ser privado de la cosa, en los casos de desapropiación, por necesidad o utilidad pública o interés social, y también en el caso de ocupación interrumpida y de buena intención de inmueble de extensa área, por más de cinco años, por considerable número de personas que, en conjunto o separadamente, hayan realizado en él obras y servicios considerados de interés social y económico relevante.

Tal dispositivo respalda a la Usucapión Especial Colectiva, instituido por el Estatuto de la Ciudad, importante en la regularización de áreas mayores que 250 metros cuadrados en los casos en los que no sea posible individualizar los terrenos ocupados por cada poseedor.

La institución de ZEIS permitió también la flexibilización de las normas ambientales visando la regularización de asentamientos en áreas ambientales protegidas, las llamadas Áreas de Preservación Permanente (APP). Una resolución del Consejo Nacional de Medio Ambiente (Resolución CONAMA $n^{\circ} 369$, de 2006) admitió la intervención o supresión de vegetación en APP para la regularización de ocupaciones irregulares de baja renta en área urbana declarada como Zona Especial de Interés Social (ZEIS) en el Plano Director u otra legislación municipal.

\section{Avances recientes}

En 2007 la Ley $n^{\circ} 11.481$ introdujo medidas dedicadas a la regularización de áreas públicas federales ocupadas de forma irregular por población de baja renta. Las regularizaciones de esas áreas pueden ser realizadas bajo el régimen de concesión de derecho real de uso (CDRU), previsto en el artículo $7^{\circ}$ del Decreto-Ley $n^{\circ} 271$, de 28 de febrero de 1967. La aplicación de este dispositivo se da especialmente en las áreas inalienables, como los terrenos de marina y aumentados, islas, márgenes de ríos federales y otras áreas, dispensándose la realización de licitaciones.

Un importante dispositivo presentado por esa ley es el auto de demarcación, por el cual son delimitadas las áreas ocupadas de interés social con base en el levantamiento de la situación existente, siendo el área demarcada, matriculada en nombre de la Unión. Desde el registro del área se procede a la regularización de las áreas ocupadas individualmente por medio de los dispositivos previstos en la legislación específica.

El año de 2009 presenta dos nuevos marcos legales para la regularización de la tenencia del suelo urbano en Brasil. La Ley no 11.952 define criterios específicos para el destino de tierras bajo la jurisdicción del Instituto Nacional de Colonización y Reforma Agraria (INCRA) para la regularización rural y urbana en los municipios de los 9 estados brasileños que componen la llamada Amazonía Legal. En esos estados, ciudades enteras o barrios se desarrollaron en tierras antes destinadas a la implementación de asentamientos rurales de la reforma agraria.

A lo largo del tiempo, algunos núcleos perdieron su vocación rural y se desarrollaron como áreas urbanas, en los cuales no solo los moradores no poseen título de propiedad de sus viviendas, como también los gobiernos locales sin el dominio de su área patrimonial se encuentran imposibilitados de invertir recursos públicos en infraestructura, equipos comunitarios y promover sus políticas 
habitacionales.

La nueva ley busca facilitar la transferencia de esas áreas para el dominio del municipio con el compromiso de realizarse la regularización de la tenencia del suelo a favor de sus efectivos ocupantes, y cría un rito para propiciar la seguridad de la posesión - fundamento del derecho a la vivienda - a millones de moradores en una región donde la cuestión de la tierra es uno de los puntos críticos del control ambiental.

Esa iniciativa se encuadra en una amplia acción que busca el ordenamiento territorial de la Región Amazónica, por la acción integrada de varios entes federales, gobiernos estaduales y municipios, visando la reducción de los conflictos agrarios, la deforestación ilegal y la ocupación desordenada de la región.

Finalmente, la Ley 11.977, de 2009, que instituye el programa habitacional del gobierno federal Ilamado Programa Mía Casa, Mi Vida, trae en su Capítulo III, el primer diploma legal al nivel federal con un conjunto de conceptos y procedimientos para enfrentar el desafío de legalizar la tenencia del suelo urbano en el país, superando las lagunas de la legislación existente.

Este capítulo, en verdad, constituía parte del Proyecto de Ley para la revisión de la Ley $n^{\circ}$ 6.766, de 1979, que trata de la parcelación del suelo para fines urbanos, en discusión en el Congreso Nacional desde 2000. Con la maduración del texto referente a la regularización de la tenencia del suelo urbano, el mismo fue agregado al texto de la nueva ley por ocasión de su edición. Entre los principales puntos de la nueva legislación se destacan:

- La definición de la regularización de la tenencia del suelo como un conjunto de medidas jurídicas, urbanísticas, ambientales y sociales que visan a la efectiva integración de los asentamientos informales a la ciudad.

- La responsabilidad del municipio por la regularización en su territorio siendo él quien pueda disciplinar, por ley, los procedimientos de regularización.

- El proyecto de regularización deberá contemplar por lo menos los aspectos urbanísticos, ambientales, de control de riesgos y de dominio envueltos en la regularización plena.

- El proyecto de regularización será aprobado directamente por el municipio, evitando complejos y demorados procesos de licenciamiento urbanístico y ambiental en otras esferas.

- La aprobación del proyecto de regularización en los casos de interés social vale como licenciamiento urbanístico y ambiental, desde que el municipio tenga órganos ambientales estructurados, no siendo necesario nuevo licenciamiento en órganos ambientales.

- La regularización de las ocupaciones en Áreas de Protección Permanente - APP insertas en áreas urbanas consolidadas será admitida, desde que el estudio técnico compruebe las mejorías de las condiciones ambientales y de vivienda de la población.

- El permiso para que el poder público realice obras de infraestructura antes que la situación dominial esté resuelta.

- La simplificación de procedimientos para regularización del dominio de parcelaciones implantadas anteriormente a la edición de la ley de parcelación del suelo urbano en 1979.

- La creación de los instrumentos de la demarcación urbanística y legitimación de la posesión, que permiten agilizar los procesos de usucapión cuando el propietario del área ocupada no existe o no se opone a la regularización. 
- El establecimiento de criterios generales simplificados para el registro de la regularización y la gratuidad del primer registro de la regularización de interés social.

La Ley $n^{\circ} 11.977$, de 2009, se constituye en importante marco legal para la regularización de la tenencia del suelo en todo el país, en conformidad con los principios del Estatuto de la Ciudad y en defensa del derecho a la vivienda de millones de brasileños.

\section{Las políticas federales para la regularización de la tenencia del suelo urbano en Brasil}

Los marcos legales relativos a la regularización del suelo urbano expuestos arriba ofrecen un menú extenso de instrumentos disponibles para los gobiernos locales para garantizar la seguridad de la posesión de las viviendas situadas en asentamientos urbanos informales.

Las acciones implementadas por las ciudades para la regularización contemplan un extenso rol de intervenciones que actúan en diversos frentes. Es de entendimiento general que no bastan las acciones que cuidan apenas de la cuestión patrimonial, siendo necesarias también un conjunto de medidas urbanísticas, ambientales y sociales que visan garantizar el pleno desarrollo de las funciones sociales de la propiedad urbana, la integración de los asentamientos a la ciudad formal, el rescate de la ciudadanía de los moradores de los asentamientos informales y la sostenibilidad de los asentamientos y de sus poblaciones.

El Cuadro 1 presenta un conjunto de medidas necesarias en un escenario ideal para que eso ocurra. Las intervenciones están reunidas según las diversas dimensiones a que pertenece cada acción, debiendo tener en mente que las mismas poseen varias interfaces de interacción entre sí, agotando apenas en el alcance de su objetivo.

\begin{tabular}{|c|c|c|}
\hline Dimensiones & Objetivos & Acciones \\
\hline Jurídica & $\begin{array}{l}\text { Garantizar y proteger el } \\
\text { derecho a la vivienda. }\end{array}$ & $\begin{array}{l}\quad \text { - Creación y aplicación } \\
\text { de instrumentos jurídicos } \\
\text { que permitan garantizar la } \\
\text { seguridad de la posesión. } \\
\quad \text { - Titulación definitiva o } \\
\text { concesión de derecho real de } \\
\text { uso de las áreas ocupadas. }\end{array}$ \\
\hline Administrativa & $\begin{array}{l}\text { Crear las condiciones para } \\
\text { que los asentamientos } \\
\text { informales irregulares } \\
\text { puedan ser reconocidos } \\
\text { oficialmente como partes } \\
\text { de la ciudad }\end{array}$ & $\begin{array}{l}\text { - Revisión de índices y } \\
\text { parámetros urbanísticos en las } \\
\text { áreas informales ocupadas. } \\
\text { - Reformulación de } \\
\text { procedimientos de aprobación y } \\
\text { licenciamiento de los proyectos } \\
\text { de reqularización. }\end{array}$ \\
\hline
\end{tabular}




\begin{tabular}{|c|c|c|}
\hline $\begin{array}{c}\text { Urbanística y } \\
\text { Ambiental }\end{array}$ & $\begin{array}{l}\quad \text { Calificación } \\
\text { e integración del } \\
\text { asentamiento a la ciudad } \\
\text { legal suministrando } \\
\text { mejores condiciones de } \\
\text { vida a la población en el } \\
\text { ámbito urbano. }\end{array}$ & $\begin{array}{l}\text { - Implantación de sistemas } \\
\text { de infraestructura. } \\
\text { - Implantación de equipos } \\
\text { públicos. } \\
\text { - Mejoría de la } \\
\text { accesibilidad y adecuación del } \\
\text { sistema viario. } \\
\text { - Calificación de los } \\
\text { espacios públicos. } \\
\text { - Control de las áreas de } \\
\text { riesgo. } \\
\text { - Recuperación de las } \\
\text { áreas ambientales degradadas. }\end{array}$ \\
\hline Habitacional & $\begin{array}{l}\quad \text { Mejoría de las } \\
\text { condiciones de las } \\
\text { viviendas para la } \\
\text { satisfacción de las } \\
\text { necesidades básicas } \\
\text { humanas. }\end{array}$ & $\begin{array}{l}\text { - Construcción de } \\
\text { unidades habitacionales } \\
\text { adecuadas. } \\
\text { - Recalificación de las } \\
\text { viviendas precarias existentes. }\end{array}$ \\
\hline Social & $\begin{array}{l}\quad \text { Rescate de la } \\
\text { ciudadanía e integración } \\
\text { de las poblaciones } \\
\text { marginadas a la sociedad }\end{array}$ & $\begin{array}{l}\text { - Políticas de género. } \\
\text { - Fortalecimiento del } \\
\text { capital social. } \\
\text { - Garantía de participación } \\
\text { y gestión urbana democrática. }\end{array}$ \\
\hline Económica & $\begin{array}{l}\text { Capacitación } \\
\text { económica de la población } \\
\text { y su permanencia en las } \\
\text { áreas regularizadas. }\end{array}$ & $\begin{array}{l}\text { - Calificación profesional. } \\
\text { - Políticas de generación } \\
\text { de renta. } \\
\text { - Regularización de } \\
\text { los pequeños negocios y } \\
\text { empresas. }\end{array}$ \\
\hline
\end{tabular}

El enfrentamiento de la cuestión de la regularización de la tenencia del suelo en Brasil ha sido conducido con muchas dificultades por gobiernos locales y estaduales, y representantes de diversas entidades públicas. Esas dificultades se suceden desde la falta de recursos materiales y técnicos por parte de las prefecturas para ejecutar las acciones de regularización, hasta dificultades impuestas por la propia legislación que, mismo ofreciendo diversos instrumentos que garantizan el derecho a la vivienda y permiten la regularización de los asentamientos informales, aún es omisa en algunos aspectos creando trabas a la regularización.

El Ministerio de las Ciudades, creado en 2003, está encargado de apoyar acciones de 
regularización en áreas urbanas en el país por medio de apoyo técnico y financiero a estados, Distrito Federal y municipios. El llamado Programa Papel Pasado utiliza recursos del Presupuesto General de la Unión, de la unidad presupuestaria del Fondo Nacional de Habitación de Interés Social - FNHIS, aumentados de las contrapartidas obligatorias de estados, municipios y Distrito Federal.

Anteriormente al Programa Papel Pasado, acciones de regularización fueron implementadas por el Programa Habitar-Brasil/BID (HBB), creado en 1999, con la aplicación de recursos de la Unión, financiados por el Banco Interamericano de Desarrollo - BID. EI HBB se desarrolló en dos subprogramas: Desarrollo Institucional de los Municipios (DI); y Urbanización de Asentamientos Subnormales (UAS). El último, destinado a la implantación y ejecución de proyectos integrados para la urbanización de asentamientos subnormales, tenía la regularización de la tenencia del suelo como un ítem obligatorio.

Los resultados muestran que muchas de las obras previstas por el programa para la urbanización de los asentamientos precarios enfrentaron problemas debido a la cuestión de registro de las tierras. Además, pocos contratos alcanzaron la regularización de la tenencia de las viviendas por medio del registro definitivo de los títulos.

Otras acciones de regularización también son implementadas por el gobierno federal, sobre las ocupaciones incidentes en áreas públicas de dominio de la Unión. En muchas de esas áreas no es posible conceder títulos de propiedad, pero apenas la Concesión de Derecho Real de Uso - CDRU, una vez que muchas de ellas son áreas inalienables según la Constitución Federal, como márgenes de lagos y ríos que bañen más de un estado.

Para esas áreas se aplica legislación propia, la Ley 11.481, de 2007, ya mencionada, que define instrumentos específicos para la regularización de las ocupaciones en esas áreas. Esta actuación del gobierno federal se da principalmente en la regularización de áreas ocupadas por población ribereña o de ribera, tradicional y "quilombola", esto es, las populaciones remanecientes de esclavos fugados.

\section{El Programa Papel Pasado}

Diferentemente de acciones de regularización de la tenencia del suelo implementadas en otros países de América Latina como México, Colombia o Perú, por ejemplo, donde el gobierno central actúa directamente en la regularización, en Brasil la actuación del gobierno central, por medio del Ministerio de las Ciudades es descentralizada. En el ámbito del pacto federativo brasileño el municipio es quien posee la atribución de ejecutar las políticas de alcance local, donde la política urbana está inserta. Siendo así, la esfera federal actúa apenas en el apoyo y en la complementación de la acción municipal, con base en la idea de la cooperación entre los entes federados.

Tal hecho es un factor de dificultad en la implementación de las acciones de regularización una vez que topa en la falta de capacidad técnica y financiera de los municipios. Asociada a esas carencias, se junta la ausencia de una política nacional de regularización unificada, que se encuentra dividida y sobrepuesta entre diferentes órganos del gobierno federal, y entre Secretarías del propio Ministerio de las Ciudades. Además, diferentemente de otros órganos de la administración pública directa, el Ministerio de las Ciudades no cuenta con unidades descentralizadas, lo que dificulta aún más un apoyo más directo a los municipios brasileños. 
Para la efectividad del apoyo prestado por el área federal fue creada la acción de Apoyo a la Regularización Sostenible de Asentamientos Informales en Áreas Urbanas, también llamado "Programa Papel Pasado". El programa tiene como objetivo específico proveer apoyo técnico, capacitar agentes públicos, y proveer apoyo financiero por medio de la transferencia de recursos del Presupuesto General de la Unión para elaboración de planes municipales de regularización e implementación de programas y acciones específicas de regularización de la tenencia del suelo, prioritariamente para la población de baja renta.

Entre 2004 y 2011, desde la creación del Ministerio de las Ciudades en 2003, el Programa Papel Pasado destinó poco más de 50 millones de reales (U\$ 25 millones) del Presupuesto General de la Unión para Municipios, Estados, Defensas Públicas y entidades de la sociedad civil para el desarrollo de acciones de regularización. Este montante de recursos representó apenas $0,6 \%$ de la dotación presupuestaria empeñada en el mismo período al Programa de Urbanización, Regularización e Integración de Asentamientos Precarios a lo cual está vinculado.

La mayor parte de las acciones apoyadas por el programa, o casi $60 \%$ de ellas se destinaron a la implementación de medidas técnicas, administrativas o jurídicas necesarias a la efectividad de la regularización patrimonial de las viviendas. Otras actividades también apoyadas con el repaso directo de recursos fueron: elaboración de proyectos de regularización, formulación o implementación de programas y planes de regularización, identificación de áreas, levantamiento cartográfico, levantamiento y catastro de moradores.

El monitoreo del Programa Papel Pasado indica que entre 2004 y 2011 fueron beneficiados directamente con recursos 187 municipios en 25 estados de la federación, para actuación en 674 asentamientos. En esos asentamientos, fueron atendidas cerca de 381 mil familias que tuvieron el proceso de regularización iniciado, habiendo sido concedidos 54,5 mil títulos. De éstos, fueron registrados apenas 26 mil títulos, o cerca del $48 \%$ de los títulos emitidos.

Es importante destacar que el número de municipios apoyados es mayor de lo que está informado, pues contando con recursos del programa, muchos no consiguieron ejecutar las acciones de regularización hasta el final, teniendo sus contratos cancelados. Los motivos de la no ejecución de los contratos pueden ser atribuidos a los factores ya relacionados anteriormente como la deficiencia de la capacidad técnica de los equipos locales, y también a dificultades operacionales, desinterés de la continuidad de las acciones con el cambio de gobiernos, problemas jurídicos que paralizaron las acciones, trabas en las notarías de inmuebles para el registro de los títulos y otros más.

Otro aspecto que ha dificultado el registro de los títulos es su alto coste para las familias de bajos ingresos o para municipios pequeños, que no consiguen arquear con los mismos.

El Ministerio de las Ciudades también monitorea las acciones de regularización urbana desarrolladas en el país por los estados y municipios, pero no apoyadas directamente por el Programa Papel Pasado. Una dificultad que se coloca en ese monitoreo es el acceso a las informaciones de los estados y municipios. La disponibilidad de informaciones confiables es de fundamental importancia para la evaluación de la efectividad de las políticas públicas, corrección de rumbos y planificación de acciones futuras.

Considerando los números reunidos por el Ministerio de las Ciudades que totalizan las informaciones disponibles para las acciones directas e indirectas de regularización en Brasil, tenemos que hasta 2011 cerca de 382 municipios desarrollaron acciones de regularización en áreas urbanas, 
atendiendo cerca de 1,6 millón de familias en 2 mil asentamientos informales. Como resultado, cerca de 327 mil títulos fueron concedidos, siendo que 111 mil fueron registrados en las notarías de registro de inmuebles, o apenas $34 \%$ de los títulos emitidos.

Si tomamos por base los datos de la Pesquisa del Perfil de los Municipios Brasileños de 2008, realizada por el IBGE, los números presentados por el programa aún están por debajo de la real necesidad de regularización en el país. Según la pesquisa del IBGE, cerca de 3.329 municipios informaron poseer favelas o parcelaciones irregulares. De esos, cerca de 861 son de municipios que poseen más de 20 mil habitantes en áreas urbanas y 214 con ciudades con más de 100 mil moradores. La gran mayoría de municipios con problemas son municipios pequeños, que no poseen recursos para desarrollar acciones de regularización.

A pesar de que la cuestión de la regularización de la tenencia del suelo está cada vez más presente en las agendas municipales, aún son pocos los municipios que promueven acciones continuadas en esa área. La Figura 2 muestra que apenas $27 \%$ de los municipios con favelas o parcelaciones irregulares, o ambos, desarrollan acciones de regularización de la tenencia del suelo. Esa proporción es reducida cuando se evalúa si estas acciones tienen soporte en legislaciones municipales de regularización o de programas destinados a atacar esa cuestión de forma continuada.

La proporción de la existencia de leyes específicas o programas de regularización cae, respectivamente para $20 \%$ y $14,4 \%$ en la totalidad de los municipios con problemas con la tenencia de la tierra. Aunque las acciones de regularización aumenten en los centros urbanos más crecidos del país, donde la informalidad de la ocupación del territorio es más crítica, el mismo estándar se repite, o sea, falta legislación específica que dé soporte a las acciones de regularización y de programas estructurados de regularización, como se muestra en la Figura 2.

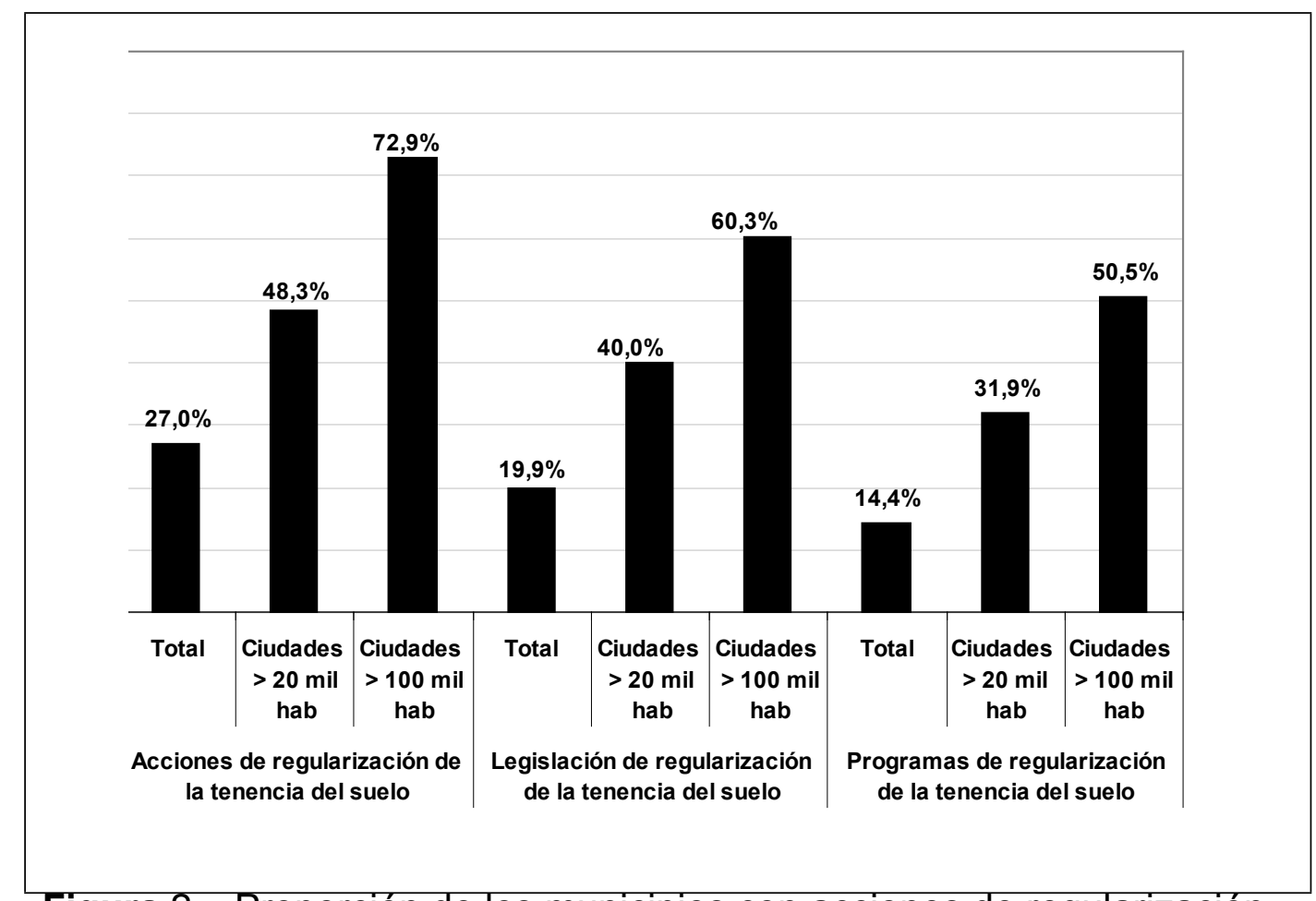

Figura 2 - Proporción de los municipios con acciones de regularización de la tenencia del suelo.

Fuente: IBGE. Perfil de los Municipios Brasileños 2008. 
Esta constatación quizá explique un poco la reducida cantidad de títulos efectivamente registrados en notaría, una vez que ese registro depende de un conjunto de normas de ámbito nacional y local que disciplinen desde el proceso de regularización, la aprobación de los proyectos de regularización y su licenciamiento ambiental y, finalmente, la resolución de cuestiones vinculadas al registro. La falta de normas que reglamenten el proceso de regularización localmente, también deja espacio para que disposiciones ad hoc puedan interferir en las acciones de regularización, trabando los procesos conforme los intereses en juego.

\section{Discusión final: Perspectivas de evolución y desafíos}

Es un hecho que mucho ya se avanzó en la construcción de mecanismos para hacer viable la regularización de la tenencia del suelo y garantizar el derecho constitucional de morada a millones de brasileños. Sin embargo, considerándose la complejidad del proceso de regularización que envuelve diversos procedimientos y de la propia diversidad del fenómeno de la informalidad, mucho aún tiene que ser hecho para alterar el actual escenario de informalidad en Brasil.

En lo que toca a la legislación federal dos cuestiones se colocan como de necesaria alteración. En primer lugar hay que definir un conjunto de normas ambientales que se apliquen específicamente a la cuestión ambiental urbana, resolviendo omisiones y solapamientos de leyes que, no habiendo sido pensadas para las áreas urbanas, son en ellas aplicadas desconsiderando las particularidades y los conflictos sociales de acceso a la tierra urbanizada y bien localizada en las ciudades. En ese sentido, la elaboración del nuevo Código Forestal Brasileño, en edición en el Congreso Federal en 2012 acoge los principales dispositivos de la Ley 11.977 de 2009, en especial la admisión de regularización de interés social de áreas de preservación en áreas urbanas.

Un segundo punto que merece atención es la revisión de algunos procedimientos en lo que atañe al registro inmobiliario, una vez que, a pesar de los avances recientes alcanzados por la revisión de la legislación federal, muchas notarías adoptan normas que extrapolan el nivel de exigencia legal. La exigencia de documentos innecesarios para el registro de la regularización por parte del Poder Judiciario Estadual, que es quien define los procedimientos a ser seguidos por las notarías, ha generado diversas trabas para el registro. Es importante que se considere el interés social de la regularización y se eliminen dispositivos y exigencias que son inocuas para garantizar mayor seguridad en las transacciones inmobiliarias, muchas veces impidiendo el registro.

Los altos precios de costas y emolumentos cobrados en el registro de la regularización han impedido también el registro de los títulos concedidos a familias de baja renta, a pesar de las gratuidades previstas en ley. Hay que compatibilizar la necesidad de conceder descuentos o mismo la gratuidad de los registros, considerando también la necesidad de mantener el equilibrio financiero de la prestación de los servicios notariales. De lo contrario, las notarías podrán atrasar el registro, fragilizando la garantía del derecho a la vivienda en los asentamientos informales.

Muchos de los avances alcanzados en la regularización en el país devienen de la creación del Ministerio de las Ciudades y de su actuación en la remoción de obstáculos jurídicos y de la formulación de acciones dirigidas a la resolución de ese pasivo en las ciudades brasileñas. Sin embargo, una cuestión que se coloca es la necesidad de definir claramente los papeles de los varios órganos envueltos en la regularización, sin solapamientos o actuaciones competidoras. La creación 
de unidades descentralizadas del Ministerio de las Ciudades, o mismo una estructura autárquica con autonomía de recursos y con unidades descentralizadas, debe ser considerada para mejorar el apoyo a los municipios en las diversas áreas de actuación del Ministerio.

En ese sentido, la propia estructuración de las acciones del Ministerio de las Ciudades debe ser evaluada, siendo importante considerar que la regularización y también la cuestión de la planificación y gestión de las ciudades deben tener un tratamiento estratégico, una vez que esas cuestiones afectan la aplicación de recursos de las demás áreas de actuación del Ministerio. Es importante que las políticas de esas áreas sean articuladas en la construcción de ciudades sostenibles y socialmente inclusivas.

En la esfera municipal es deseable la edición de leyes específicas de regularización, que incorporen los avances alcanzados por la legislación federal adecuándolos a las especificidades locales y a las determinaciones del Plano Director local. Sin embargo, es importante que no ocurra lo mismo que aconteció por ocasión de la edición de la Ley de Parcelación del Suelo en 1979, cuando muchos municipios crearon leyes de parcelación por veces más restrictivas y exigentes que la propia ley federal, uno de los factores que puede haber aportado para el aumento de la informalidad urbana, al limitar la oferta de habitaciones en cantidad y tipo adecuadas a la población de baja renta.

Vale resaltar que además de crearse un marco legal adecuado para la regularización de la tenencia del suelo, la efectividad de las acciones de regularización pasa también por la continuidad de las políticas formuladas en nivel federal y local, que deben ser ampliadas y mejoradas constantemente. Para que eso ocurra deben ser garantizados los recursos necesarios para la continuidad de las acciones, equipos técnicos capacitados y sistemas de información estructurados que permitan el monitoreo y la constante evaluación de las acciones, fundamental para una buena gestión del desarrollo urbano.

\section{Referencias bibliográficas}

BRASIL. Estatuto da cidade: Guia para implementação pelos municípios e cidadãos: Lei $\mathrm{n}^{\circ}$ 10.257, de 10 de julho de 2001, 3 ed. Brasília: Câmara dos Deputados, Coordenação de Publicações. 2005.

. IBGE. Ministério do Planejamento, Orçamento e Gestão. Censo Demográfico 2000. http:// www.sidra.ibge.gov.br.

. IBGE. Ministério do Planejamento, Orçamento e Gestão. Perfil dos Municípios Brasileiros 2008. http://www.ibge.gov.br/home/estatistica/economia/perfilmunic/2008/default.shtm.

Assentamentos Precários no Brasil Urbano. Brasília: Ministério das Cidades. Secretaria Nacional de Habitação. Elaboração: Centro de Estudos da Metrópole/CEBRAP, 2007.

. Déficit Habitacional no Brasil 2007. Brasília: Ministério das Cidades. Secretaria Nacional de Habitação. Elaboração: Fundação João Pinheiro, Centro de Estatística e Informações. 2009 
. Ações integradas de Urbanização de Assentamentos Precários. Curso à Distância. Brasília/ São Paulo: Ministério das Cidades/Aliança de Cidades, 2009.

Dowall, D. (2006) Brazil's urban land and housing markets: How well are they doing? Background paper prepared for the Lincoln Institute of Land Policy. Cambridge, MA: Lincoln Institute of Land Policy.

Guedes, P. M. e Oliveira, N. V. (2006) A Democratização do Consumo, em Braudel Papers. N 39. Instituto Fernand Braudel de Economia Mundial.

Maricato, E. (1996) Metrópole na Periferia do Capitalismo: Ilegalidade, Desigualdade e Violência. São Paulo: Hucitec.

. (1999) A Terra é um nó na sociedade brasileira... Também nas cidades. Cultura Vozes. № 6, ano 93, v. 93. p. 7-22.

Mello, C. (1982) Natureza Jurídica do Zoneamento; Efeitos. Revista de Direito Administrativo, n. 147, p. 23-38, jan./mar. Rio de Janeiro

Perez, M. D. (2007) Lacerda na Guanabara: A reconstrução do Rio de Janeiro nos anos 1960. Rio de Janeiro: Odisséia Editorial.

Rolnik, R. (1997) A Cidade e a Lei: Legislação, Política Urbana e Territórios na Cidade de São Paulo. São Paulo: Livros Studio Nobel: Fapesp.

- Regulação Urbanística e Exclusão Social no Estado de São Paulo: Mitos e Verdades. Revista de Direito Imobiliário, RDI, n. 46, 126-133, 1999.

Soto, H. (2001) O Mistério do Capital. Rio de Janeiro: Record. 